\title{
A Primary Care-Public Health Partnership Addressing Homelessness, Serious Mental Illness, and Health Disparities
}

\author{
Lara Carson Weinstein, MD, MPH, Marianna D. LaNoue, PhD, \\ James D. Plumb, MD, MPH, Hannab King, BS, Brianna, Stein, MD, \\ and Sam Tsemberis, $P h D$
}

Background: People with histories of homelessness and serious mental illness experience profound health disparities. Housing First is an evidenced-based practice that is working to end homelessness for these individuals through a combination of permanent housing and community-based supports.

Methods: The Jefferson Department of Family and Community Medicine and a Housing First agency, Pathways to Housing-PA, has formed a partnership to address multiple levels of health care needs for this group. We present a preliminary program evaluation of this partnership using the framework of the patient-centered medical home and the "10 Essential Public Health Services."

Results: Preliminary program evaluation results suggest that this partnership is evolving to function as an integrated person-centered health home and an effective local public health monitoring system.

Conclusion: The Pathways to Housing-PA/Jefferson Department of Family and Community Medicine partnership represents a community of solution, and multiple measures provide preliminary evidence that this model is feasible and can address the "grand challenges" of integrated community health services. (J Am Board Fam Med 2013;26:279-287.)

Keywords: Community Medicine, Delivery of Health Care, Homeless Persons, Mental Health, Public Health

Those who emerge from the shadows of homelessness bring the disparities in the U.S. health care system into sharper focus. We describe the development and evaluation of a community of solution ${ }^{1}$ that addresses the dual problems of chronic home-

This article was externally peer reviewed.

Submitted 1 September 2012; revised 14 December 2012; accepted 4 January 2013.

From the Department of Family and Community Medicine, Jefferson Medical College, Thomas Jefferson University, Philadelphia, PA (LCW, MDL, JDP, BS); Jefferson Medical College, Thomas Jefferson University, Philadelphia, PA (HK); Pathways to Housing, New York, NY (ST).

Funding: Supported was provided in part by grants from the US Department of Health and Human Services (DHHS) Health Resources and Services Administration (HRSA): nos. D55HP10334 and D58HPO5138 (LCW); nos. D54HP23289 and D56HP20783 (MDL); and no. D56HP20783 (HK).

Disclaimer: The contents of this article are solely the responsibility of the authors and do not necessarily represent the official views of the DHHS/HRSA.

Conflict of interest: none declared.

Corresponding author: Lara Carson Weinstein, MD, MPH, Department of Family and Community Medicine, 1015 Walnut St, Suite 401, Philadelphia, PÄ, 19107 (E-mail: lara.weinstein@jefferson.edu). lessness and poor health outcomes experienced by people with serious mental illness (SMI) through a partnership between an academic medical center and a Housing First program. Housing First, an innovative and effective housing and treatment model, ${ }^{2}$ works to end homelessness for people with SMI by offering immediate access to permanent supportive housing and intensive community-based interdisciplinary supports. However, once housed, people continue to face numerous, often untreated chronic health conditions, suggesting that a systematic approach to population health improvement is needed. Primary care and patient-centered medical homes (PCMHs) can play a significant role in helping to meet public health needs. ${ }^{3,4}$ This article offers an example of this process, in which an extended PCMH in the Thomas Jefferson University Department of Family and Community Medicine (DFCM) and a local nonprofit Housing First agency, Pathways to Housing-PA (PTH-PA), have partnered successfully to better meet the individual and population health needs of formerly homeless 
people with SMI. Through a fusion of a PCMH model with elements of community-oriented primary care and a public health outreach, a unique and synergistic community of solution emerged.

\section{Background}

People with SMI are represented disproportionally among the chronically homeless. By some estimates, people with SMI die approximately 25 years earlier than those in the general U.S. population. ${ }^{5}$ Cardiovascular conditions and other treatable and preventable chronic diseases contribute heavily to excess morbidity and mortality in this population. ${ }^{5,6}$ In addition, the health problems of people experiencing homelessness are substantial and complex. Most chronically homeless individuals have multiple disabilities including SMI, chronic medical conditions, and co-occurring substance use disorders. ${ }^{7}$ Homeless populations in the United States experience a mortality rate 3 to 4 times that of the general population, with the highest mortality ratios seen in the 18 - to 54 -year-old age group. ${ }^{8}$ These unacceptable disparities persist despite most chronically homeless people regularly interfacing with multiple systems including shelters, hospitals, mental health and drug and alcohol services, criminal justice, and welfare. ${ }^{9}$ Given the interactions with multiple acute care systems and the complex medical and behavioral health care needs of the population, including needs for chronic disease management and intensive care coordination, a personcentered health care home coupled with housing seems a good community-based solution to enhancing population outcomes.

PTH-PA is a Housing First program that was brought to Philadelphia in 2008 through a request from the City of Philadelphia for assistance in addressing the problem of chronic homelessness. PTH-PA is based on the original Pathways to Housing-New York model. To date, PTH-PA has engaged 249 people, housed 183 people, and reports a $92 \%$ housing placement rate among a population that previously was considered not "housing ready" or "difficult to reach." ${ }^{10}$ With the support of the Philadelphia Department of Behavioral Health and Office of Supportive Housing, PTH-PA has expanded over the past 4 years and now includes 4 support teams. While the Pathways model traditionally has targeted people with experiences of chronic homelessness and SMI, PTH-PA also re- cently included special programs for veterans with SMI who are homeless, people living with HIV/ AIDS, and people with chronic substance use dependence or addiction. Currently, the clients are predominately men (68\%) and African American (71\%), with a mean age of 51 years. With respect to axis I psychiatric disorders, those seen most frequently are schizophrenia spectrum disorders (42\%) followed by mood disorders (37\%). (Please note the above population summary statistics and all following population statistics do not include the veterans team because of data sharing restructions.) These categories are not mutually exclusive.

\section{Intervention}

The original Pathways support team, based on the Assertive Community Treatment model, includes social workers, a nurse, a psychiatrist, a peer specialist, a vocational specialist, and a drug and alcohol counselor. ${ }^{11}$ Experiences of local service providers with the target population both in Philadelphia and New York revealed significant difficulty in connecting individuals to primary care. This is a population that often has a long history of negative experiences in the mental health and primary care systems and comprises those who are either reluctant to seek or avoid seeking medical care. The Thomas Jefferson University DFCM has a 20-year history of providing flexible, on-site health services to homeless and formerly homeless populations. ${ }^{12}$ On the basis of this knowledge and experience, a formal partnership was formed between the DFCM and PTH-PA, and a primary care physician was embedded into the PTH-PA Assertive Community Treatment team to provide on-site primary care and population-based health monitoring and services. ${ }^{13}$ The partnership draws from general departmental resources, the St. Elizabeth's community satellite clinic, and the main family medicine practice, Jefferson Family Medicine Associates, which is a level-3 medical home recognized by the National Committee for Quality Assurance. Additional clinical, evaluation, and educational partnerships have been formed with the Jefferson's Center for Urban Health, Department of Emergency Medicine, School of Nursing, and School of Public Health (Figure 1).

The topic of the intersection of primary care with public health efforts, including the potential overlap of outcomes, is relatively new. The 2012 
Figure 1. Pathways to Housing-PA/Department of Family and Community Medicine partnership. JFMA, Jefferson Family Medicine Associates; TJU, Thomas Jefferson University.

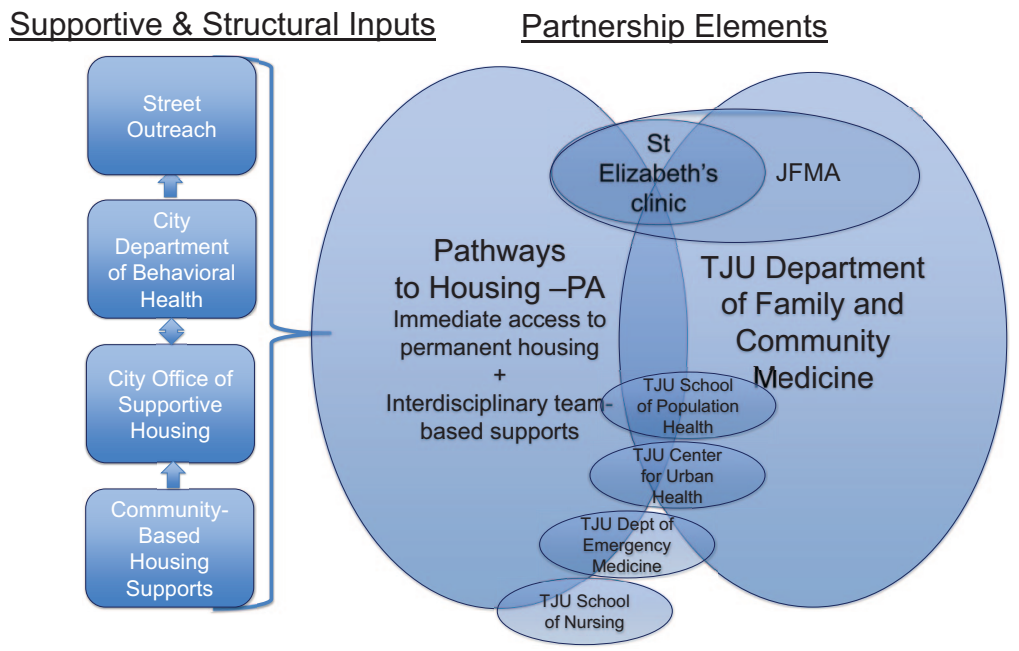

Institute of Medicine report ${ }^{3}$ makes clear that a universal template for integration is impossible because of the varied settings in which primary care is delivered and the unique population health needs across different settings. We recognized that the DFCM/PTH-PA partnership builds on and extends the recommendations of the key principles of the $\mathrm{PCMH}^{14}$ and the "10 Essential Public Health Services." ${ }^{15}$ As such, we describe below the method used for evaluating the adherence of our program model to these principles.

\section{Methods}

We performed a preliminary formative program evaluation for the purposes of directing program- ming and funding efforts. As a part of that effort, 2 authors (LCW and MDL) analyzed the overlap between program components and $\mathrm{PCMH}$ elements, which is shown in Table $1 .{ }^{14} \mathrm{We}$ also analyzed the program using the Local Public Health System Performance Assessment Instrument ${ }^{16}$ (version 2.0) to characterize the manner in and degree to which the program is meeting the performance standards set forth in the "10 Essential Public Health Services"15 (Table 2). Following the example of Lebrun, ${ }^{4}$ we assigned Likert values to each of the 10 essential services to represent the level to which each activity/standard named in the assessment is accomplished in our partnership $(0=$ not accomplished, 1 = minimally accomplished,

Table 1. Elements of the Patient-Centered Medical Home (PCMH) at Pathways to Housing-PA (PTH-PA) ${ }^{14}$

\begin{tabular}{|c|c|}
\hline PCMH & PTH-PA \\
\hline Personal physician & $\begin{array}{l}25 \% \text { of PTH-PA clients have the on-site family physician as their PCP. Efforts } \\
\text { are ongoing to link all clients with a PCP either on site or in the community } \\
\text { because almost } 50 \% \text { of clients do not have a known PCP. }\end{array}$ \\
\hline Physician-directed medical practice & A family physician is the medical director of PTH-PA. \\
\hline Whole-person orientation & $\begin{array}{l}\text { PTH-PA offers fully integrated primary and behavioral health care. The } \\
\text { principles of mental health recovery are a core value. }\end{array}$ \\
\hline $\begin{array}{l}\text { Care is coordinated and integrated across all } \\
\text { elements of the complex health care } \\
\text { system }\end{array}$ & $\begin{array}{l}\text { All care transitions are coordinated closely by the PTH-PA staff. On-site } \\
\text { meetings frequently occur between PTH-PA staff and the staff of outside } \\
\text { care facilities. }\end{array}$ \\
\hline Quality and safety & $\begin{array}{l}\text { PTH- PA has developed the infrastructure for ongoing continuous quality } \\
\text { improvement. Clients actively participate through community-based } \\
\text { participatory research and a consumer health advisory board. }\end{array}$ \\
\hline Enhanced access & Appointment scheduling is open access and staff is available 24 hours a day. \\
\hline Payment & $\begin{array}{l}\text { Payment for family physician time is not built into the behavioral health billing } \\
\text { structure. Payment relies on contracts and in-kind support. }\end{array}$ \\
\hline
\end{tabular}

PCP, primary care physician 
Table 2. The 10 Essential Public Health Services and Pathways to Housing-PA (PTH-PA) ${ }^{15,16}$

10 Essential Public Health Services

PTH-PA

Score*

1. Monitor health status to identify community health problems.

2. Diagnose and investigate health problems and health hazards in the community.

3. Inform, educate, and empower people about health issues.

4. Mobilize community partnerships to identify and solve health problems.

5. Develop policies and plans that support individual and community health efforts.

6. Enforce laws and regulations that protect health and ensure safety.

7. Link people to needed personal health services and assure the provision of health care when otherwise unavailable.

8. Assure a competent public and personal health care workforce.

9. Evaluate effectiveness, accessibility, and quality of personal and population-based health services.

10. Research new insights and innovative solutions to health problems.

Infrastructure for monitoring health is being developed through the Pathways Population Health Database and Metabolic Syndrome Screening Project.

On-site primary care is available for all clients. Larger health issues such as fire safety and summer heat assessments are monitored across the population.

PTH-PA has monthly wellness groups and periodic groups about specific health topics.

PTH- PA has multiple partnerships with community organizations, Thomas Jefferson University, and the Philadelphia Department of Behavioral Health.

PTH-PA has policies on medication management and metabolic syndrome screening and is developing a fire safety policy.

PTH-PA has developed clear safety policies and procedures.

On-site primary and behavioral health care is available for all clients regardless of insurance status. Home visits are available for clients unable to come to the office. All clients are supported in community-based care linkages.

PTH-PA and Jefferson Department of Family and Community Medicine partner in training students using a homeless health rotation and clerkship model.

PTH-PA has several ongoing quality improvement programs.

The PTH Housing First model is based on dedication to research and innovation.

${ }^{*} 0=$ No, $1=$ minimal, $2=$ moderate, $3=$ significant, and $4=$ optimal.

$2=$ moderately accomplished, $3=$ significantly accomplished, 4 = optimal accomplishment). We independently rated each item and then met to discuss the ratings. In cases where the initial rating was not the same, we used the discussion toolboxes as guidance to gain consensus. The scores for each item are provided in Table 2 . In this preliminary program evaluation, we achieved a total score of 32 using the Likert-scaled Local Public Health System Performance Assessment Instrument, representing an average score midway between significant and optimal across items.

\section{Results}

The results of our preliminary program analyses are shown in Tables 1 and 2, which describe the overlapping features of the model program with elements of the $\mathrm{PCMH}^{14}$ and with the " 10 Essential Public Health Services." 15 The success of this model program relies largely on the extension of the existing academic $\mathrm{PCMH}$, and therefore it is reassuring to recognize that these $\mathrm{PCMH}$ elements translated well into this setting for the delivery of primary care and, furthermore, that the emerging promise of the $\mathrm{PCMH}$ in meeting public health goals is coming to fruition in this setting.

Below we describe in more detail the ways in which the partnership is addressing the " 10 Essential Public Health Services." 15 These results are intended to highlight the success of the partnership in meeting public health objectives and fostering important public health outcomes, with an emphasis on selected public health services of the PTH-PA program.

\section{Essential Public Health Service 1: Monitor Health Status to Identify Community Health Problems; Essential Public Health Service 2: Diagnose and Investigate Health Problems and Health Hazards in the Community}

The Pathways Population Health Database health service research project began in 2009 as a chronic disease registry, created by one of the authors (LCW) to better understand the health status of 
the population. The project was expanded in 2011 as the Pathways Prevention Project to track receipt of screenings for substance abuse, chronic disease, cancer, infectious disease, and immunizations. In 2012, the project was expanded to include a specific metabolic syndrome monitoring protocol for all program participants taking antipsychotic medications: the Metabolic Syndrome Screening Project (MSSP). The MSSP was developed directly in response to a mandate from the City Department of Public Health for programs to develop a policy around screening for metabolic syndrome. Table 3 shows the results of the Pathways Prevention Project and the MSSP.

Currently, 77\% of the PTH-PA population has a chronic disease and $59 \%$ have $\geq 2$ diseases. The most common diagnoses are hypertension (43\%), orthopedic diseaseC (23\%), HIV (14\%; because of a special HIV/AIDS housing program within PTH-PA), asthma (14\%), and hepatitis C (14\%). According to 2011 data, $67 \%$ of the population are overweight or obese, $82 \%$ use tobacco, and $50 \%$ use substances. For the total population, alcohol, tobacco, drug, and hypertension screenings were documented most frequently: at least once between the time of entry to the PTH-PA program and the time of chart review ( $\geq 75 \%$ of the total population received screening). The least commonly documented $(\leq 5 \%)$ preventive services were pneumococcal vaccine for clients $\geq 65$ years old and a podiatry visit. Of people taking antipsychotic medications, 29\% have had at least 3 documented and measured metabolic syndrome criteria. Blood pressure was measured more often $(81 \%)$, followed by body mass index (71\%) and fasting glucose $(43 \%)$. Formal programs to improve prevention and screening have been instituted during the annual nursing assessments and during medical and psychiatric visits. Obtaining results of screening and prevention services accomplished via outside providers remains an ongoing challenge. This has limited the accuracy of our preliminary results, but work is underway to increase the use of medical release forms to better capture information from outside providers.

\section{Essential Public Health Service 3: Inform, Educate, and Empower People About Health Issues}

In 2010 we undertook a community-based participatory research project focused on health and health care decision making through a series of 9
Table 3. Pathways Population Receipt of Preventive Services

\begin{tabular}{|c|c|}
\hline Preventive Service Measure* & $\begin{array}{l}\text { Clients Receiving } \\
\text { Services }\end{array}$ \\
\hline Alcohol misuse screening & $152(91)$ \\
\hline Tobacco use screening & $150(90)$ \\
\hline Drug use screening & $148(89)$ \\
\hline Hypertension screening & $130(78)$ \\
\hline Obesity screening & $125(75)$ \\
\hline Intimate partner violence screening & $100(60)$ \\
\hline Type 2 DM screening & $88(53)$ \\
\hline Hyperlipidemia screening & $54(32)$ \\
\hline HIV infection & $40(24)$ \\
\hline Hepatitis $\mathrm{C}$ infection & $32(19)$ \\
\hline Pneumococcal vaccine (high risk) & $30(19)^{\dagger}$ \\
\hline Cervical cancer screening & $10(19)^{\ddagger}$ \\
\hline Seasonal influenza vaccine $(2011)$ & $28(17)$ \\
\hline Breast cancer screening & $7(14)^{\S}$ \\
\hline Colorectal cancer screening & $13(13)^{\mathbb{I}}$ \\
\hline Seasonal influenza vaccine (2010) & $22(13)$ \\
\hline Dental exam & $12(7)$ \\
\hline Ophthalmology visit & $12(7)$ \\
\hline Podiatry visit & $4(2)$ \\
\hline Pneumococcal vaccine ( $\geq 65$ years old) & $0(0)^{\|}$ \\
\hline \multicolumn{2}{|l|}{$\begin{array}{l}\text { Metabolic syndrome screening } \\
\qquad(\mathrm{n}=59)\end{array}$} \\
\hline Blood pressure & $50(85)$ \\
\hline Body mass index & $44(75)$ \\
\hline Fasting glucose & $26(44)$ \\
\hline Fasting lipids & $22(37)$ \\
\hline Waist circumference & $3(5)$ \\
\hline
\end{tabular}

Values shown as $\mathrm{n}(\%)$.

*Since entering the program, Pathways clients have received 167 preventive services.

${ }^{\dagger}$ Percentage of total population eligible for pneumococcal vaccination and $<65$ years old.

${ }^{\ddagger}$ Percentage of the female population $\geq 21$ years old.

\$Percentage of the female population $\geq 40$ years old.

"Percentage of the total population $\geq 50$ years old.

"Percentage of total population $\geq 65$ years old.

DM, diabetes mellitus.

focus groups with 11 PTH-PA clients. This project revealed several key insights: without housing, access to health care may have a limited effect on health (except in the case of painful, life-threatening conditions); housing has the potential to change profoundly how people perceive and attend to their health care priorities; and for individuals with experiences of both homelessness and psychiatric disability, the prospect of finally being able to authentically consider "health" brings with it new implications for interfacing with the health care system. 
In 2011 we piloted the Stanford Chronic Disease Self-Management Program, with separate groups for women and men. This program included a qualitative assessment of clients' views on self-management of chronic disease. Results of the analysis of the women's group included the finding of major themes centering on the topics of current health concerns, such as aging, pain, and breathing, and health-related behaviors such as dietary choices and self-management of disease. Many women noted the contrast of healthrelated behaviors when living on the streets versus living in an apartment. The interface of mental and physical health figured prominently in health concerns. The majority of women noted an emerging high sense of control over and self-efficacy toward their own health. As a result of these initial efforts, a client health advisory board has been established, which meets quarterly, and a women's research and advocacy collaborative has been initiated to explore women's health issues further.

\section{Essential Public Health Service 7: Link People to Needed Personal Health Services and Assure the Provision of Health Care When Otherwise Unavailable}

On-site primary and behavioral health care is available for all clients regardless of insurance status. Home visits are available for clients unable to come to the office. All clients are supported in community-based care linkages. In keeping with the Housing First principle of consumer choice, clients may choose an outside health care provider if they wish. The staff directs individuals with acute or complex problems to the on-site physician if they have no other source of care. As a result, the on-site primary care physician is the personal physician for approximately 70 of the 183 housed clients. It is unlikely that these individuals would have ongoing access to primary care without this on-site service.

\section{Essential Public Health Service 8: Assure a Competent Public and Personal Health Care Workforce}

Educational programs are in place at PTH-PA for family medicine residents, medical students, nursing students, and masters in public health students at Thomas Jefferson University. Residents spend time during their internship and third-year com- munity blocks providing direct on-site care at PTH-PA. A "Medical/Community Partnerships to End Homelessness" elective is available for Jefferson fourth-year medical students, which includes time at PTH-PA and St. Elizabeth's. The resident and medical student rotations are supported in part by residency training grants and academic administrative unit grants funded by the Health Resources and Services Administration (HRSA). First-year students can participate in the quality improvement and research programs at PTH-PA through a summer research assistantship, also supported by a HRSA grant. PTH-PA is a community health clinical site placement for Jefferson seniorlevel nursing students. Finally, PTH-PA has served as both a clerkship site and basis for capstone projects for Jefferson medical and public health students who are completing their masters in public health, resulting in a local fusion of medical and public health education.

\section{Discussion}

This article describes initial efforts to monitor and improve the health of a population of formerly homeless individuals with SMI who are now in the PTH-PA Housing First program through a partnership with the Jefferson DFCM. Preliminary program evaluation results suggest that this partnership is evolving to function as an integrated person-centered health home and an effective local public health monitoring system. In addition, we have raised significantly staff and client awareness of physical health issues, resulting in increased engagement in ongoing care and screenings. Efforts are underway to quantify continuity rates and to track use of emergency services. The most recent analysis of the expanded population health database confirms high rates of chronic disease, as found in initial studies. ${ }^{13}$ The finding of relatively low rates of preventive health and screening for metabolic syndrome has resulted in ongoing quality improvement projects to address these deficiencies. Through the community-based participatory research projects, clients have been empowered to take ownership of their ongoing health issues, and, importantly, a core group of clients have become local and national advocates for programs that combine housing with health care for homeless people. The group has presented at national conferences, such as the American Public Health As- 
sociation annual meeting, and homeless service reform movements, such as the 100,000 Homes Campaign.

Our partnership forms a community of solution in which "the problem can be [better] defined, dealt with and solved." In 2010, the Folsom Group produced an updated series of 13 grand challenges to "facilitate a vision for nation-wide integrated patient-centered community health services." ${ }^{1} \mathrm{We}$ realized that the funding, structure, organization, and leadership of PTH-PA made it uniquely situated to impact positively population health outcomes, and we aligned our focus to meet these goals. This resulted in a community-tailored union of a full-scope health care home and a Housing First organization, which explicitly addresses some of the "grand challenges" of the Folsom Report, specifically grand challenges 2, 3, 9, and 10 . Figure 2 shows how the PTH-PA community of solution addresses these grand challenges.
One positive element of the funding mechanisms that have made these partnerships possible has been HRSA grants, which have as their focus health care systems research and evaluation and primary care training, and have provided an integral funding mechanism for these partnerships. For example, HRSA funding partially supported the pilot work of the primary care physician, and continues to support many of the educational activities. This blending of funding mechanisms to include those which address health systems research, medical and behavioral health outcomes research, and 'social determinants of health' studies is important to realize the goal of fostering better population health through community partnerships. ${ }^{12}$

\section{Challenges}

Although we are somewhat satisfied with our initial efforts with the PTH-PA program, significant challenges remain. The greatest of these is sustainabil-

Figure 2. Addressing the grand challenges for integrating community health services. PTH-PA, Pathways to Housing-PA; SMI, serious mental illness.

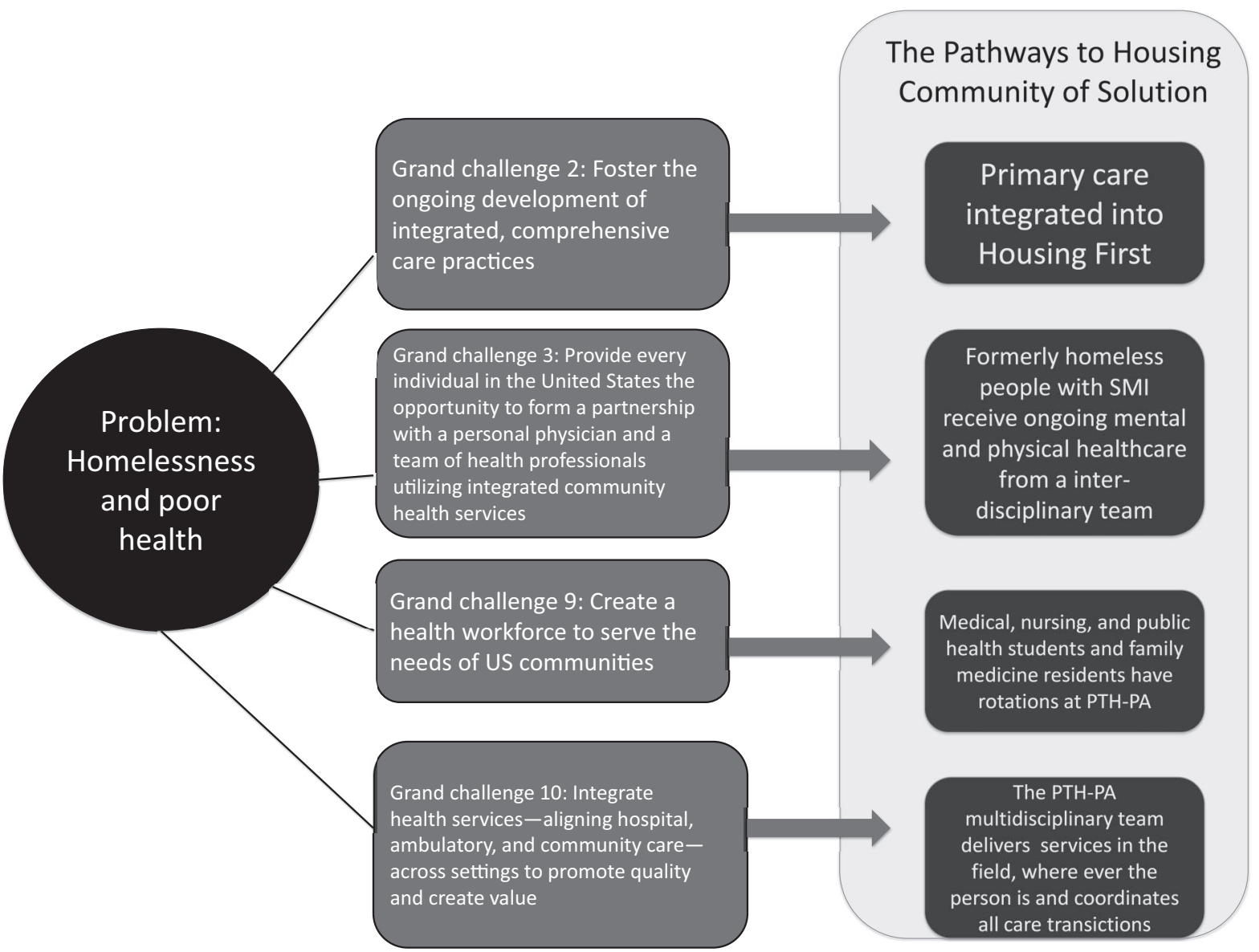


ity. The services of the embedded primary care physician are not able to be reimbursed under current insurance mechanisms. Services currently are provided through a DFCM contract with PTH-PA combined with in-kind departmental support. New models of reimbursement through the $\mathrm{PCMH}$ structure and accountable care organizations may improve this situation. However, while federal and nonfederal behavioral health organizations such as the Substance Abuse and Mental Health Service Administration and the National Council of Behavioral Health care are developing and reporting on the integration of this type of specialized care for individuals with SMI, these models have not been discussed widely in the family medicine literature.

Another significant challenge is that of workforce development and enhancement, both in family medicine and community psychiatry. We believe that our educational programs for residents and medical students will begin to increase the comfort level of medical providers when working with individuals with SMI and collaborating with behavioral health providers in community settings. Both the issues of sustainability and workforce training limit the potential for scaling up and disseminating our current model. The "community health champion" is the embedded primary care physician. This model requires training of primary care physicians in more population-centric models of care. We believe the program itself helps facilitate this goal. In addition, a HRSA-funded interdisciplinary and interprofessional joint graduate degree 5-year grant to the DFCM is developing multiple cohorts of students with population health knowledge, skills, and attitudes.

\section{Conclusion}

Homeless people with SMI in the United States experience profound health disparities. Supportive housing models such as Housing First are working to end homelessness and promote recovery in this population. Combining on-site primary care and population health management with Housing First offers significant opportunities for improving the health of this severely marginalized group. The PTH-PA/Jefferson DFCM Partnership represents a community of solution and multiple measures provide preliminary evidence that this model is feasible. Ongoing research and program evaluation is underway to determine the effectiveness of the model and, importantly, to inform future policy and system changes to improve the health of formerly homeless people with SMI and create a sustainable, integrated medical home.

The authors thank Richard Wender, MD, chair of the Jefferson Department of Family and Community Medicine; Christine Simiriglia, MS, executive director of Pathways to Housing-PA; and the staff of Jefferson Family Medicine Associates, St. Elizabeth's Health Center, and Pathways to Housing-PA for their continued dedication and support of this work.

\section{References}

1. Folsom Group. Communities of solution: the Folsom Report revisited. Ann Fam Med 2012;10: 250-60.

2. Substance Abuse and Mental Health Service Administration, US Department of Health and Human Services. Best practices for providers: Housing First. Available from http://homeless.samhsa.gov/channel/ housing-first-447.aspx. Accessed March 13, 2013.

3. Institute of Medicine. Primary care and public health: exploring integration to improve public health. Washington, DC: National Academies Press; 2012.

4. Lebrun LA, Shi L, Chowdhury J, et al. Primary care and public health activities in select US health centers: documenting successes, barriers, and lessons learned. Am J Public Health 2012;102(Suppl 3): S383-91.

5. Morden NE, Mistler LA, Weeks WB, Bartels SJ. Health care for patients with serious mental illness: family medicine's role. J Am Board Fam Med 2009;22:187-95.

6. Gold KJ, Kilbourne AM, Valenstein M. Primary care of patients with serious mental illness: your chance to make a difference. J Fam Pract 2008;57: 515-25.

7. National Alliance to End Homelessness. Chronic homelessness. Federal policy brief, March 11, 2007. Available from http://www.endhomelessness.org/ library/entry/chronic-homelessness. Accessed March 13, 2013.

8. O'Connell JJ. Premature mortality in homeless populations: a review of the literature. December 2005. Available from http://santabarbarastreetmedicine. org/wordpress/wp-content/uploads/2011/04/Premature MortalityFinal.pdf. Accessed March 13, 2013.

9. Cancellier R, Mangan M, Kania K, Metraux S, Maguire M, Hoffman R. City of Philadelphia homeless death review. 2009-2010 Report. April 2012. Available from http://www.phila.gov/health/pdfs/ 2009-2010\%20Homeless\%20Death\%20Review\%20 Report.pdf. Accessed March 13, 2013.

10. Fairmount Ventures, Inc. Evaluation of Pathways to Housing PA. January 2011. Available from https:// 
www. pathwaystohousing.org/uploads/PTHPAProgramEvaluation.pdf. Accessed March 13, 2013.

11. Tsemberis S, Gulcur L, Nakae M. Housing first, consumer choice, and harm reduction for homeless individuals with a dual diagnosis. Am J Public Health 2004;94:651-6.

12. Plumb J, Weinstein LC, Brawer R, Scott K. Community-based partnerships for improving chronic disease management. Prim Care 2012;39:433-47.

13. Weinstein LC, Henwood BF, Matejkowski J, Santana A. Moving from street to home: health status of entrants to a housing first program. J Prim Care Community Health 2011;2:11-5.
14. Patient Centered Primary Care Collaborative. Joint principles of the patient-centered medical home. Available from https://www.pcpcc.net/joint-principles. Accessed March 13, 2013.

15. Centers for Disease Control and Prevention. National Public Health Performance Standards Program (NPHPSP). 10 Essential public health services. Available from http://www.cdc.gov/nphpsp/essentialservices. html. Accessed March 13, 2013.

16. Center for Disease Control and Prevention. Local public health system performance assessment instrument 2007. Version 2.0. Available from http://www.cdc.gov/nphpsp/ documents/local_v_1_omb_0920-0555.pdf. 